\title{
Tapentadol extended release for the management of chronic neck pain
}

\author{
Domenico Billeci' \\ Flaminia Coluzzi² \\ 'Division of Neurosurgery, \\ Ca'Foncello Hospital, University \\ of Padova, Treviso, ${ }^{2}$ Department \\ of Medical and Surgical Sciences \\ and Biotechnologies, Unit of \\ Anaesthesiology, Intensive Care \\ Medicine, and Pain Therapy, Faculty \\ of Pharmacy and Medicine, Sapienza \\ University of Rome, Latina, Italy
}

This article was published in the following Dove Press journal: Journal of Pain Research

2 March 2017

Number of times this article has been viewed

Background: The role of opioids in the management of chronic neck pain is still poorly investigated. No data are available on tapentadol extended release (ER). In this article, we present 54 patients with moderate-to-severe chronic neck pain treated with tapentadol ER.

Patients and methods: Patients received tapentadol ER $100 \mathrm{mg} / \mathrm{day}$; dosage was then adjusted according to clinical needs. The following parameters were recorded: pain; Douleur Neuropathique 4 score; Neck Disability Index score; range of motion; pain-associated sleep interference; quality of life (Short Form [36] Health Survey); Patient Global Impression of Change (PGIC); Clinician GIC; opioid-related adverse effects; and need for other analgesics. Results: A total of 44 of 54 patients completed the 12-week observation. Tapentadol ER daily doses increased from $100 \mathrm{mg}$ /day to a mean (standard deviation) dosage of 204.5 (102.8) $\mathrm{mg}$ /day at the final evaluation. Mean pain intensity at movement significantly decreased from baseline (8.1 [1.1]) to all time points $(P<0.01)$. At baseline, $70 \%$ of patients presented a positive neuropathic component. This percentage dropped to $23 \%$ after 12 weeks. Tapentadol improved Neck Disability Index scores from 55.6 (18.6) at baseline to 19.7 (20.9) at the final evaluation $(P<0.01)$. Tapentadol significantly improved neck range of motion in all three planes of motion, particularly in lateral flexion. Quality of life significantly improved in all Short Form (36) Health Survey subscales $(P<0.01)$ and in both physical and mental status $(P<0.01)$. Based on PGIC results, approximately $90 \%$ of patients rated their overall condition as much/very much improved. Tapentadol was well tolerated: no patients discontinued due to side effects. The use of other analgesics was reduced during the observed period.

Conclusion: Our results suggest that tapentadol ER, started at $100 \mathrm{mg} / \mathrm{day}$, is effective and well tolerated in patients with moderate-to-severe chronic neck pain, including opioid-naïve subjects. Patients can expect a decrease in pain, an improvement in neck function, and a decrease in neuropathic symptoms.

Keywords: tapentadol, chronic neck pain, neuropathic pain, opioids, Neck Disability Index, range of motion

\section{Introduction}

Neck pain is a common disabling disease associated with a high socioeconomic burden. More than $50 \%$ of the middle-aged population show clinical or radiological signs of cervical spine disease; however, this condition is often asymptomatic. The estimated 1 -year incidence of neck pain ranges between $10.4 \%$ and $21 \%$, mean prevalence in the general population is $23 \%$, and it is slightly higher in women in their fifth decade of life. ${ }^{1}$ The prevalence of cervical spine disease increases with age, and a higher incidence has been observed in cigarettes smokers, computer workers, or subjects in occupations
Correspondence: Flaminia Coluzzi Department of Medical and Surgical Sciences and Biotechnologies, Unit of Anaesthesiology, Intensive Care Medicine, and Pain Therapy Faculty of Pharmacy and Medicine, Sapienza University of Rome, 79 Corso della Repubblica, Latina 04100, Italy

Email flaminia.coluzzi@uniromal.it 
that require repetitive use of the upper extremities, such as violinists and pilots. ${ }^{2,3}$ The economic burden of neck pain is high, due to medical visits, physiotherapy, pharmacological and surgical treatments, working days lost, and compensation expenditure. Specifically, $>40 \%$ of patients with neck injuries miss $>1$ week of work/year and are prone to recurrence within 1 year from the first episode. ${ }^{4}$

Neck pain may be caused by different conditions that compress, irritate, and eventually destroy sensitive structures, such as the annulus fibrosus, posterior longitudinal ligament, and the capsule of the zygapophyseal joints. ${ }^{5}$ Cervical radiculopathy, defined as pain radiating along the distribution of a cervical nerve root, can arise from "soft disk" herniation (compression of the nerve likely leads to localized ischemia and nerve damage), cervical spondylosis (degenerative changes of the neural foramen leading to bony osteophytes that impinge on the cervical nerve root), or both. ${ }^{6}$ Other causes of neck pain are facet-joint pain (with somatic referral to the shoulders, scapula, and upper limb), myofascial syndrome (associated with trigger points located in the skeletal muscles), or soft-tissue lesions. ${ }^{7}$ After an acute episode, the resolution of neck pain is not necessarily maintained. ${ }^{8}$ Pain relapses and chronicity are common among patients with neck pain and cervical radiculopathy, leading to significant impairment in quality of life, activity limitation, and disability. The reasons for progressing from acute to subacute pain and subsequently to chronic pain are still not completely understood, but awareness is growing on the role of central sensitization..$^{9,10}$

Despite the high frequency of cervical disease, few studies are currently available on the efficacy of different pharmacological treatments for neck pain. Similarly, there is scant evidence supporting cervical epidural injections ${ }^{11}$ and intraarticular facet-joint injections, ${ }^{12}$ however, the number of these procedures has dramatically increased over the last few years.

The majority of available trials have evaluated the shortand long-term efficacy of surgical approaches (anterior cervical diskectomy, cervical disk arthroplasty, and posterior decompression), ${ }^{13,14}$ manipulations, ${ }^{15}$ physical therapies and exercise,${ }^{16}$ acupuncture,${ }^{17}$ and cognitive behavioral therapy. ${ }^{18}$ Therefore, most guidelines are focused on nonpharmacological treatment of neck pain, ${ }^{19}$ while the only published recommendations on the pharmacological approach are based on expert opinion, with some evidence being extrapolated from clinical trials of analgesic drugs for back pain or other musculoskeletal diseases. ${ }^{20}$ Paracetamol is an effective first-line choice for mild-to-moderate neck pain; on the other hand, nonsteroidal anti-inflammatory drugs (NSAIDs), despite being more effective than placebo, ${ }^{21}$ are not satisfactory in chronic pain conditions. For people with neck pain lasting $>12$ weeks, trial therapy with amitriptyline or gabapentinoids should be considered. ${ }^{20,22}$

Persistent and chronic back pain are indicative of ongoing central sensitization, characterized by phenomena of functional and structural neuroplasticity. ${ }^{23}$ Due to the paucity of clinical studies on chronic neck pain, evidence of central sensitization is sparse; however, it has been able to be clinically observed in a subgroup of patients. ${ }^{24}$ In these conditions, central analgesics may be more appropriate, since they target the opioidergic system and the descending inhibitory pathways. ${ }^{10}$ The efficacy of opioids in neck pain and/or cervical radiculopathy has been poorly investigated to date, ${ }^{25-27}$ whereas there is evidence supporting their use in low-back pain (LBP). ${ }^{28}$

In particular, tapentadol, the innovative dual therapy that acts as a $\mu$-opioid-receptor agonist and norepinephrinereuptake inhibitor, is effective in the treatment of moderatesevere LBP. Tapentadol extended release (ER) is as effective as controlled-release oxycodone ${ }^{29}$ and more effective than the oxycodone-naloxone combination in patients with mixed back pain presenting a neuropathic component. ${ }^{30}$ However, no studies are available on the use of tapentadol ER in patients suffering from neck pain. The aim of this study was to evaluate the efficacy and tolerability of tapentadol ER in patients with moderate-severe chronic neck pain.

\section{Patients and methods Patients}

According to the Italian National Health Service and the Local Health Unit institutional review board, this case series was an observational study of normal clinical practice and treatment and did not require formal review or approval. In accordance with the local protocols of routine clinical practice, tapentadol ER was used in a sample of 54 consecutive patients suffering from chronic neck pain, and written informed consent was obtained from all patients, allowing anonymous use of their clinical data.

Inclusion criteria were: 1) men and nonpregnant, nonlactating women $\geq 18$ years old; 2 ) clinical diagnosis of moderate-severe chronic (at least 3 months of history prior to screening) neck pain ( $>4$ at movement on a numerical rating scale [NRS] of $0-10$ ), unresponsive to step 1 analgesic ladder drugs (nonopioid drugs), or occasional use of step 2 opioids for moderate pain (codeine or tramadol); and 3 ) cervical degenerative disease, causing axial neck pain or radiculopathy. 
Exclusion criteria were: 1) a history of or laboratory values reflecting severe renal or hepatic impairment; 2) use of monoamine oxidase inhibitors within 14 days prior to screening; 3) history of drug abuse; 4) cognitive failure; 5) severe psychiatric disorders; 6) cervical degenerative disease, causing myelopathy; 7) planned cervical surgery; (8) malignancy or spinal tumor; 9) compression fractures or luxation of the cervical column; and 10) spinal infections.

\section{Treatment}

Each patient initially received twice-daily oral doses of tapentadol ER $50 \mathrm{mg}$. During the titration phase, according to our clinical practice, at a minimum of 3-day intervals, upward dose titration was allowed in increments of twice-daily tapentadol ER $50 \mathrm{mg}$. Doses were managed on the basis of clinical response to ensure adequate pain relief without dose-limiting toxicity.

For patients on a stable prestudy regimen of nonopioid analgesics, such as paracetamol, NSAIDs, or adjuvant drugs (such as antidepressants or anticonvulsants), these medications were continued according to medical judgment if they were well tolerated. Prior World Health Organization (WHO) step 2 opioids were discontinued. WHO step 2 and step 3 opioids, except for the study drug, were prohibited during the study. Symptomatic drugs (antiemetics and laxatives) and corticosteroids were permitted according to clinical needs.

\section{Evaluations}

In accordance with our clinical practice, patients were visited or contacted by telephone at least once weekly in the first month of treatment, in order to monitor therapy and make dosage adjustments as needed according to clinical status. Data were recorded at baseline before the initiation of treatment (week 0), at weekly intervals for 2 weeks (week 1 , week 2), and then at 4 weeks (week 4), 8 weeks (week 8), and 12 weeks (week 12).

\section{End points}

The primary end point of our evaluation was the change in average pain intensity from baseline (week 0 ) to week 12 . Pain intensity at rest and at movement were monitored using patients' self-reports on an 11-point NRS from 0 (no pain at all) to 10 (worst imaginable pain). Secondary end points were comprised as follows.

\section{Changes in neuropathic pain symptoms}

These were evaluated using the Douleur Neuropathique (DN)-4 (score 0-10). ${ }^{31}$ The DN4 is a screening tool for neuropathic pain consisting of interview questions and physical tests. If the score is $\geq 4$, the pain is considered neuropathic.

\section{Neck-specific disability}

This was measured with the Neck Disability Index (NDI; $0-100 \%) .{ }^{32}$ The NDI is a revised form of the Oswestry Disability Index. It is a validated ten-section questionnaire that measures activity limitations due to neck pain: each section is scored $0-5$. If one section is missed, the total score is calculated on the completed sections only. The original report provided scoring intervals for interpretation, as follows: 0-4 (no disability), 5-14 (mild disability), 15-24 (moderate disability), 25-34 (severe disability), and above 34 (complete disability).

\section{Neck range of motion}

All cervical active range of motion (ROM) measures were performed in the upright sitting position. Neck flexion/extension (range $0^{\circ}-45^{\circ}$ ) and neck side-bending (range $0^{\circ}-45^{\circ}$ ) were measured with an inclinometer by asking the patient to flex their head forward and to extend the neck backward as far as possible, and to move each ear to its homolateral shoulder. Neck rotation (range $0^{\circ}-80^{\circ}$ ) was measured with a universal goniometer by asking the patient to rotate in each direction as far as possible. ${ }^{33}$ Neck ROM variation from week 0 to week 12 is presented as a percentage, calculated as: (ROM value at week $12-$ ROM value at week 0 )/ROM maximum value $\times 100$.

\section{Quality of life}

Quality of life was valuated using the Short Form (36) (SF-36) Health Survey at week 0 and week 12 . The SF-36 ${ }^{34}$ is a 36-item survey that evaluates eight dimensions of functional health and well-being (physical functioning, role - physical, bodily pain, general health, vitality, social functioning, role - emotional, and mental health), each scored from 0 ("lowest level of health") to 100 ("highest level of health"). The individual SF-36 item scores were summarized into physical and mental health composite scores.

\section{Pain-associated sleep interference}

Pain-associated sleep interference (PSI), assessed on an 11-point NRS ranging from 0 (pain does not interfere with sleep) to 10 (pain completely interferes with sleep).

\section{Global Impression of Change}

Patient Global Impression of Change (PGIC) and Clinician GIC (CGIC) were used to evaluate patients' global health status. The PGIC and CGIC were evaluated at the end of the 
study (week 12), using a 7-point descriptive scale: very much worse, much worse, minimally worse, no change, minimally improved, much improved, and very much improved.

\section{Adverse effects}

Adverse effects associated with opioid therapy (such as nausea and vomiting, drowsiness, confusion, constipation, dry mouth, myoclonus, and sweating) were recorded. The need for other analgesics, antiemetic agents, and laxatives was evaluated as well.

\section{Statistical methods}

All data were collected on a web-based platform (IESSS [Ibis enhanced spontaneous study system]) specifically planned for spontaneous research and analyzed by IBIS Informatica (Milan, Italy) using descriptive statistics. $P<0.05$ was considered statistically significant. All analyses were performed using SAS 9.4 software (SAS Institute Inc, Cary, NC, USA).

Analysis of continuous variables (tapentadol dosing, pain intensity at rest, pain intensity on movement, and cervical ROM), measured on scheduled visits during the study period, was performed using analysis of variance with repeated measures without grouping factors and with multiple comparisons versus baseline value, adjusting the chosen significance level $(P=0.05)$ with the Bonferroni method. Changes in quality of life (SF-36) between baseline score and end of study score were analyzed using Student's paired $t$-test. Analysis of discrete variables (DN4 score and NDI) was performed using the nonparametric Wilcoxon signed-rank test, with comparisons versus baseline value. Analysis of frequency of patients with neuropathic pain was performed using McNemar's test.

\section{Results}

\section{Study population}

The study included 54 patients. Demographic and baseline disease characteristics are presented in Table 1. All patients were Caucasian, and $64.8 \%$ were female (35 of 54). The mean (standard deviation [SD]) age was 56.4 (12.1) years, with 42 (77.8\%) patients aged $\geq 65$ years. In total, 63\% (34 of 54) of patients had a diagnosis of spondyloarthrosis and one in three (18 of 54) presented discal herniation.

More than four patients in five $(81.5 \%, 44$ of 54$)$ were still on treatment at the end of the study. Ten patients discontinued treatment due to protocol violation $(n=2)$, withdrawal of consent for any reason $(n=3)$, unsatisfactory analgesia $(n=1)$,
Table I Demographic data at baseline (week 0)

\begin{tabular}{|c|c|c|}
\hline & Mean/n & SD $/ \%$ \\
\hline Age (years), mean and SD & 56.4 & 12.1 \\
\hline \multicolumn{3}{|l|}{ Age-group, $\mathrm{n}$ and $\%$} \\
\hline$<65$ years & 42 & 77.8 \\
\hline$\geq 65$ years & 12 & 22.2 \\
\hline \multicolumn{3}{|l|}{ Sex, $\mathrm{n}$ and $\%$} \\
\hline Male & 19 & 35.2 \\
\hline Female & 35 & 64.8 \\
\hline Body weight $(\mathrm{kg})$, mean and SD & 72.6 & 13.8 \\
\hline BMI $\left(\mathrm{kg} / \mathrm{m}^{2}\right)$, mean and SD & 26.1 & 4.3 \\
\hline \multicolumn{3}{|l|}{ Neck disease, $\mathrm{n}$ and \% } \\
\hline Spondyloarthrosis & 34 & 63 \\
\hline Cervical stenosis & 6 & II.I \\
\hline Discal herniation & 18 & 33.3 \\
\hline Failed surgery & 2 & 3.7 \\
\hline Spondylodiscitis & 0 & \\
\hline Other & 3 & 5.6 \\
\hline \multicolumn{3}{|l|}{ Duration of pain, $n$ and $\%$} \\
\hline $3-6$ months & 26 & 48.1 \\
\hline$>6$ months & 21 & 38.9 \\
\hline Missing & 7 & 13 \\
\hline \multicolumn{3}{|l|}{$\mathrm{DN} 4, \mathrm{n}$ and $\%$} \\
\hline$<4$ & 14 & 25.9 \\
\hline$\geq 4$ & 40 & 74.1 \\
\hline \multicolumn{3}{|l|}{ Previous treatment, $\mathrm{n}$ and $\%$} \\
\hline Pharmacotherapy & 35 & 64.8 \\
\hline Surgery & 2 & 3.7 \\
\hline Physiotherapy & 18 & 33.3 \\
\hline
\end{tabular}

Abbreviations: SD, standard deviation; BMI, body mass index; DN, neuropathic pain.

loss to follow-up $(n=3)$, or other reasons $(n=1)$. No patients discontinued due to adverse events. The main analysis population thus included 44 patients. Over the study period, mean daily doses of tapentadol PR increased from $100 \mathrm{mg}$ /day at the beginning of the study to $204.5(102.8) \mathrm{mg} /$ day at the final evaluation. The highest recorded daily dose was $400 \mathrm{mg} / \mathrm{day}$, in six $(13.6 \%)$ patients.

\section{Pain intensity}

Mean pain-intensity score at baseline was 6.8 (2.1) at rest and 8.8 (1.1) at movement. Mean change at week 12 (primary end point) was $-5.1(2.3, P<0.01)$ at rest and $-5.9(2.6, P<0.01)$ on movement. After the first week of treatment, mean pain was significantly reduced to $4.7(2.3, P<0.01)$ at rest and 6.7 $(2.5, P<0.01)$ on movement (Figure 1$)$.

\section{Secondary efficacy end points}

DN4 mean values significantly decreased from 4.1 (2) at baseline to $1.9(2.1)$ at week $12(P<0.01)$. At baseline, values were negative $(<4)$ and positive $(\geq 4)$ for the presence of 


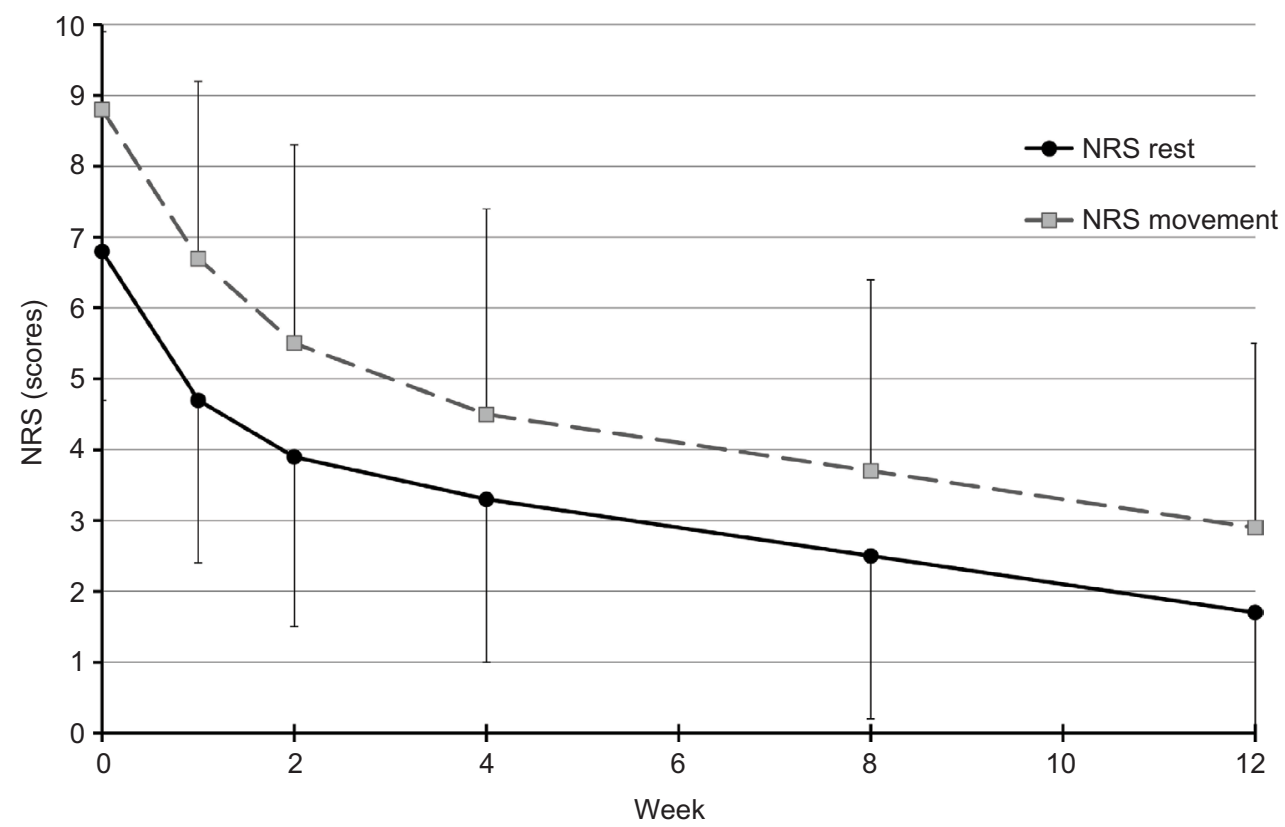

Figure I Mean and SD pain intensity (I I-point NRS) over time (observed-case analysis) at rest and on movement. Abbreviations: SD, standard deviation; NRS, numeric rating scale.

neuropathic pain in $13(30 \%)$ and $31(70 \%)$ patients, respectively. After 12 weeks, only $23 \%$ of patients were positive $(P<0.01$ vs baseline) (Figure 2). Mean NDI scores significantly improved at all times of evaluation, from 55.6 (18.6) at week 0 to $19.7(20.9)$ at week $12(P<0.001)$ (Figure 3).

Pain-free active neck ROM significantly improved in all three planes of motion over the course of the study $(P<0.01)$. Pre/posttreatment effect sizes were large for all the outcomes (Table 2). Percentage of neck ROM improvement was higher for lateral flexion in both sides compared with other planes of motion (Figure 4). Significant improvements were observed in all SF-36 domain scores from baseline to final evaluation $(P<0.01$ for all eight scale scores), as well as in both SF-36 physical and mental composite scores (all $P<0.001$ ) (Figures 5 and 6).

Mean PSI significantly decreased from 6.4 (3.1) at baseline to 1.9 (2.7) at final evaluation. Differences versus baseline values were statistically significant at all time intervals $(P<0.01)$. At the end of the 12 weeks of treatment, $88.6 \%$ of patients experienced pain-intensity reduction at movement of $30 \%$ or greater and $68.2 \%$ of $50 \%$ or greater.

Quality of sleep was significantly improved $(P<0.01)$ from the first week of treatment, with $79.5 \%$ of patients reporting $\geq 30 \%$ reduction in PSI at week 12 . With respect to PGIC, the percentage of patients who rated their pain as "much/very much improved" was $88.6 \%$ (39 of 54 ). At the CGIC evaluation, $93.1 \%$ (41 of 54) of caregivers rated the patients' overall condition at week 12 as "much/very much improved".

The most common opioid-related adverse events were dizziness $(13.7 \%)$, constipation $(9.1 \%)$, nausea $(7.8 \%)$, drowsiness (7.8\%), and vomiting (3.8\%). Some symptoms varied in prevalence during the study period (Table 3 ). The incidence of constipation increased from $5.6 \%$ at baseline to $9.1 \%$ at week 12 . Nausea, vomiting, and drowsiness increased at week 1 and week 2, and totally disappeared from week 4 to week 12 in all patients. Dizziness increased at week 1 (9.4\%) and week 2 (13.7), and progressively decreased to $2.3 \%$ at week 12 . No patients reported sweating or dry mouth, and only one case of headache at week 2 was recorded. No correlation was observed between tapentadol doses and incidence of side effects.

\section{Tolerability and concomitant medications}

The use of other analgesics was relatively modest at baseline: $12(22.2 \%)$ patients were using NSAIDs, eleven (20.4\%) paracetamol, seven (13.0\%) anticonvulsants, and three (5.6\%) antidepressants; six were on (11.1\%) step 2 opioids, three (5.6\%) corticosteroids, and two (3.7\%) topical drugs. Most patients reduced their use of other analgesics during the study period. At week 4, no patients were taking NSAIDs, corticosteroids, or step 2 opioids. Paracetamol and anticonvulsants were discontinued by nine ( $81.8 \%$ ) and two (28.6\%) patients, respectively (Table 4). Few patients required antiemetics 


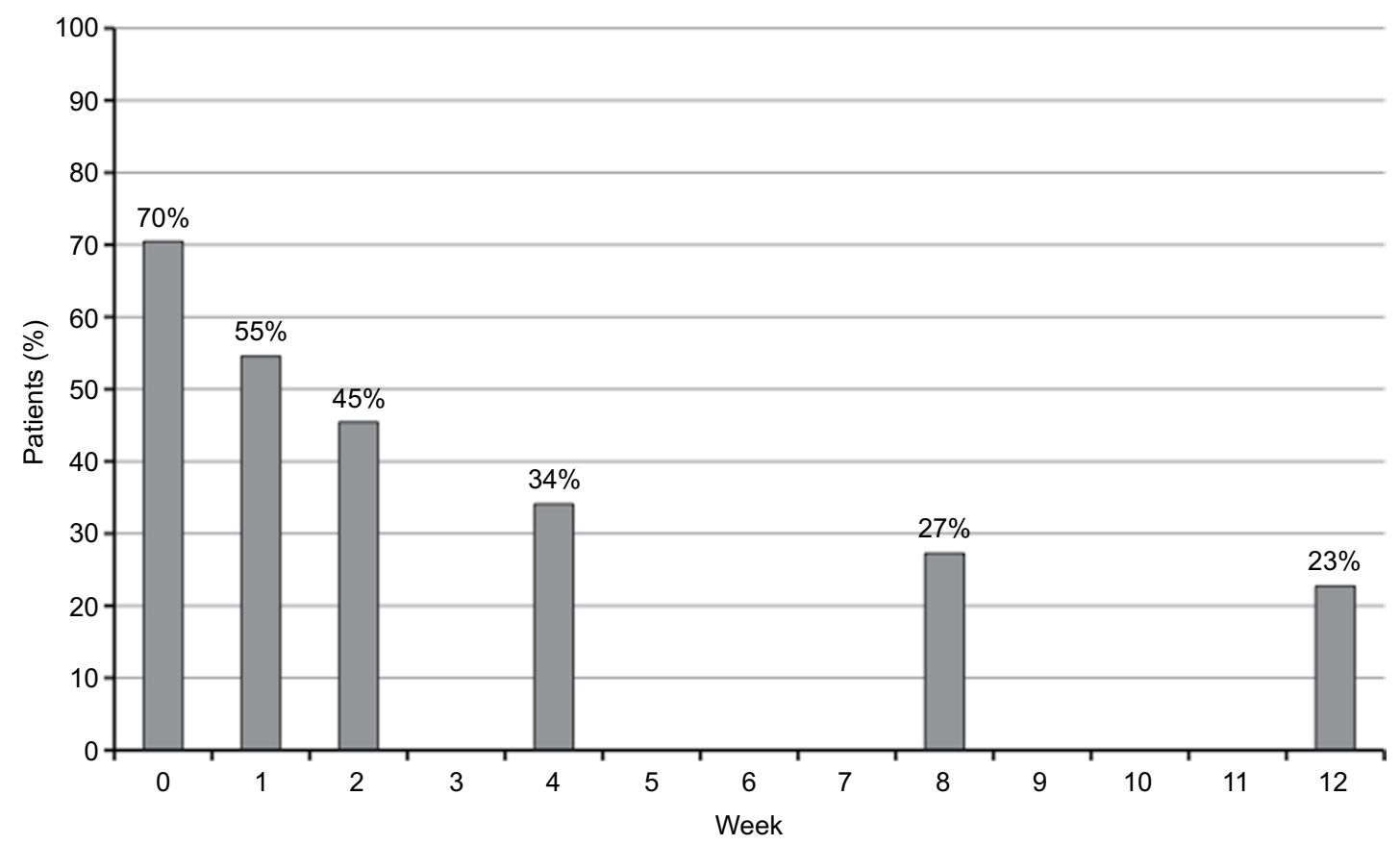

Figure 2 Percentage of patients with neuropathic pain 4 score $\geq 4$ from baseline to week 12 (final evaluation).

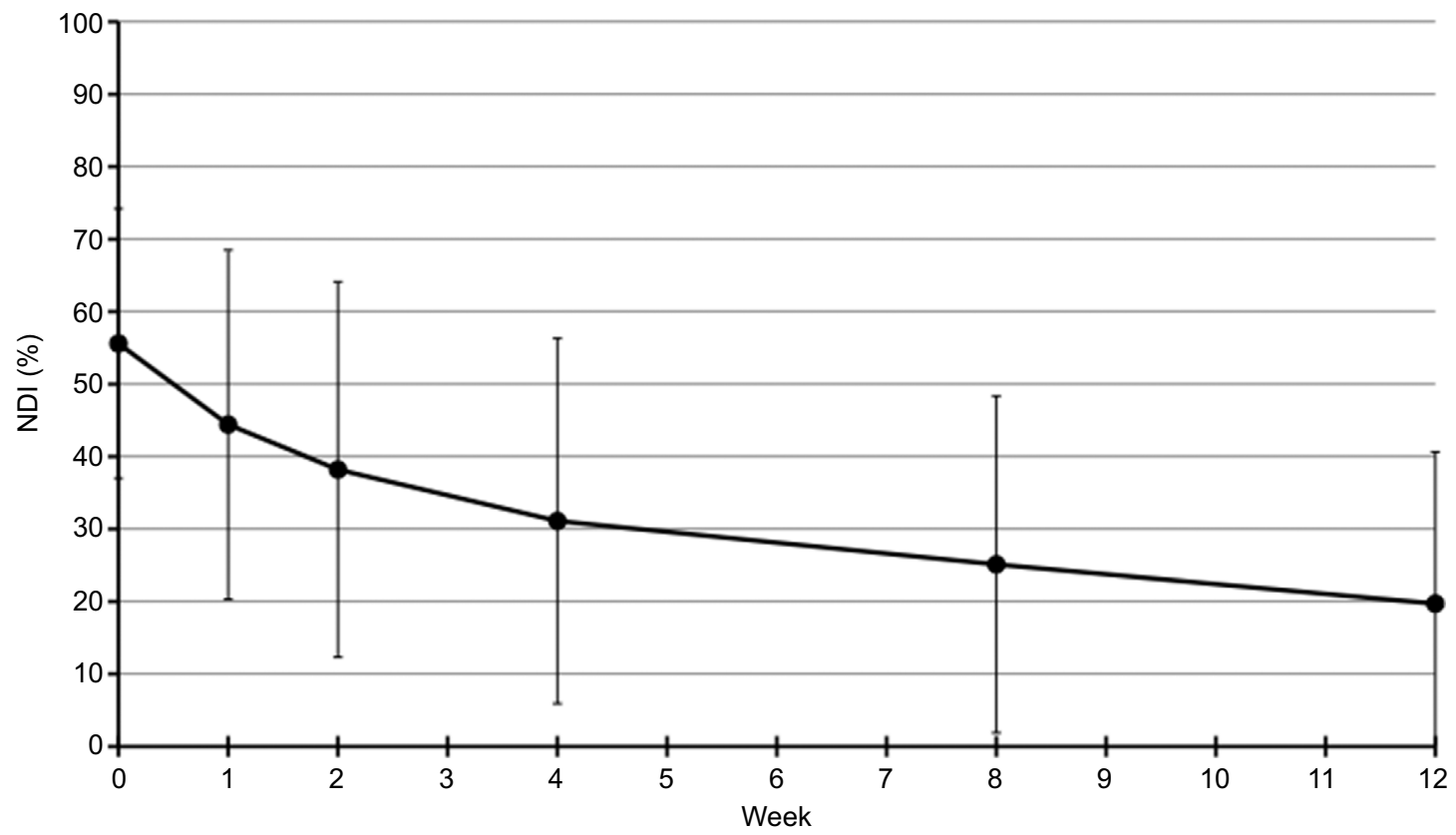

Figure 3 Neck Disability Index (NDI; mean and SD) from baseline to week 12 (final evaluation).

Notes: 55.6\% (SD 18.6) at baseline; 44.4\% (SD 24.I) at week I; 38.2\% (SD 25.9) at week 2; 3I.I\% (SD 25.2) at week 4; $25.1 \%$ (SD 23.2 ) at week 8; I9.7\% (SD 20.9) at week I2. Abbreviation: SD, standard deviation.

(up to $5.7 \%$ ), and the proportion of patients taking laxatives increased from $1.8 \%$ at baseline to $6.8 \%$ at week 12 .

\section{Discussion}

Chronic neck pain has a complex etiology. Most patients affected present a neuropathic pain component, which is difficult to manage with simple analgesics (paracetamol, NSAIDs, and weak opioids). ${ }^{35}$ The neuropathic pain component may have detrimental effects on health-related quality of life; therefore, it should be managed by adding adjuvant drugs to traditional analgesics or by using drugs able to address different components of pain, given their dual mechanism of action. ${ }^{36}$ 
Table 2 Neck ROM at weeks 0 and 12

\begin{tabular}{|c|c|c|c|c|c|c|}
\hline \multirow[t]{2}{*}{ Neck ROM (normal values) } & \multicolumn{2}{|l|}{ Week 0} & \multicolumn{2}{|l|}{ Week I2 } & \multirow{2}{*}{$\frac{\text { Pre/postvariation }}{\%}$} & \multirow[t]{2}{*}{ P-value } \\
\hline & Mean (SD) & $\%$ & Mean (SD) & $\%$ & & \\
\hline Flexion $\left(0^{\circ}-45^{\circ}\right)$ & $31.9(10)$ & 70.9 & $37.9(9.3)$ & 84.2 & 13.3 & $<0.01$ \\
\hline Extension $\left(0^{\circ}-45^{\circ}\right)$ & $24.8(I I)$ & 55.1 & $37(9.4)$ & 82.2 & 27.1 & $<0.01$ \\
\hline Right lateral flexion $\left(0^{\circ}-45^{\circ}\right)$ & $20.4(9.7)$ & 45.3 & $36(6.7)$ & 80 & 34.7 & $<0.01$ \\
\hline Left lateral flexion $\left(0^{\circ}-45^{\circ}\right)$ & $19.9(9.2)$ & 44.2 & $35.8(6.7)$ & 79.6 & 35.5 & $<0.01$ \\
\hline Right rotation $\left(0^{\circ}-80^{\circ}\right)$ & $44.7(17.8)$ & 55.9 & $64.1(11.1)$ & 80.1 & 24.3 & $<0.01$ \\
\hline Left rotation $\left(0^{\circ}-80^{\circ}\right)$ & $46.3(17.3)$ & 57.9 & $64.5(10.5)$ & 80.6 & 22.7 & $<0.01$ \\
\hline
\end{tabular}

Abbreviations: ROM, range of motion; SD, standard deviation.

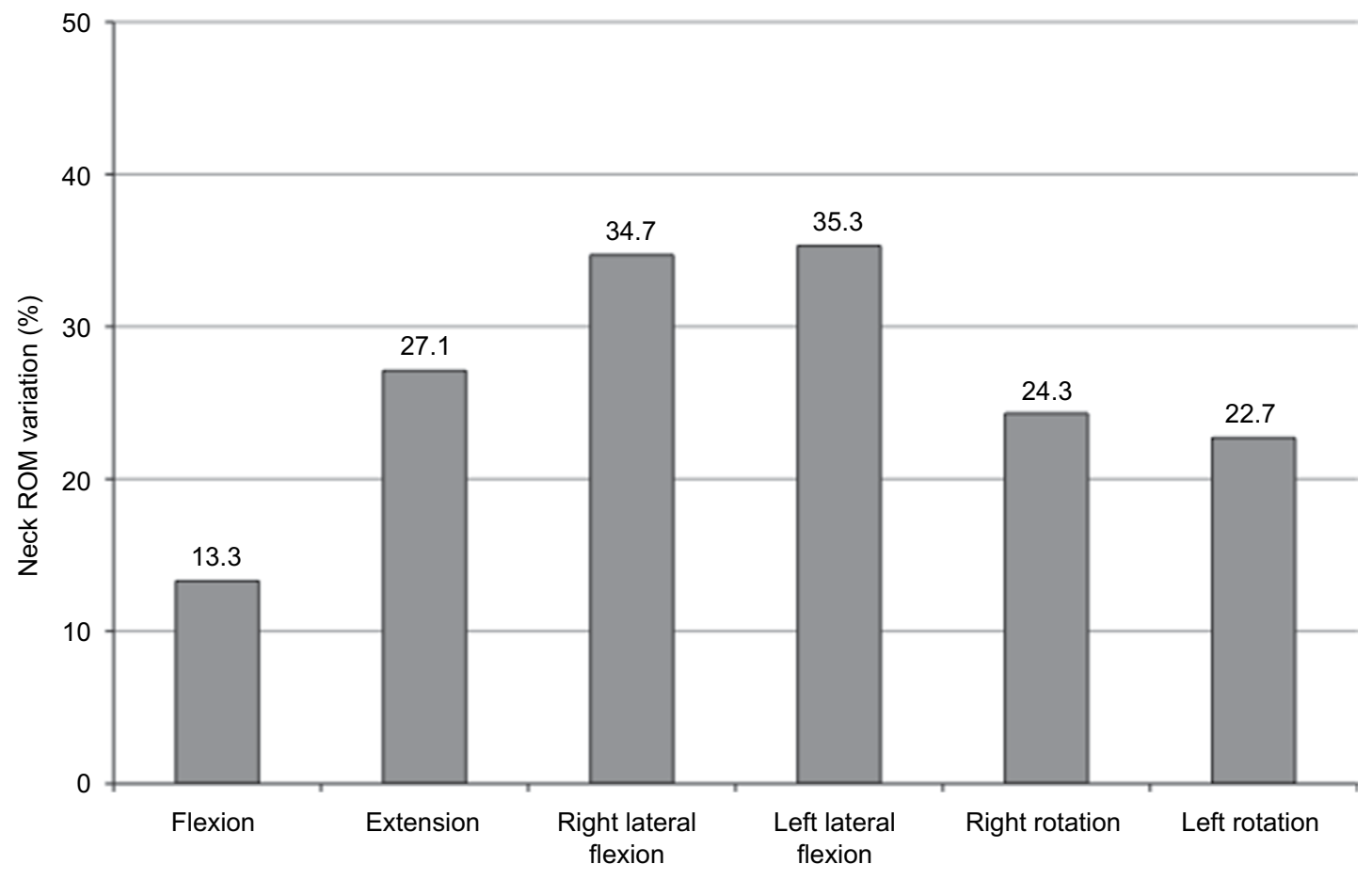

Figure 4 Percentage of neck ROM variation from baseline to week 12 (final evaluation). Abbreviation: ROM, range of motion.

The current literature on neck pain and cervical radiculopathy is poor in respect of clinical trials on the efficacy and tolerability of analgesic drugs, specifically opioids. However, in clinical practice, opioids are among the most common therapeutic choices, as suggested by two studies on the effects of chronic use of these drugs on the outcomes of cervical surgery. ${ }^{26,37}$ Controlled-release oxycodone ${ }^{25}$ and hydromorphon $e^{27}$ have been successfully used in the management of chronic neck pain.

However, traditional opioids are not specifically effective in neuropathic pain conditions. Conversely, the innovative dual-acting drug tapentadol ER was effective in other forms of mixed pain, such as LBP with a neuropathic component ${ }^{30}$ and cancer pain arising from bone metastases. ${ }^{38}$ To our knowledge, this is the first report of the efficacy of tapentadol ER in patients with chronic moderate-severe neck pain. Tapentadol ER is usually associated with better analgesia compared with traditional opioids in chronic mixed pain, with a better tolerability profile, due to its lower affinity for the $\mu$-opioid receptor.

In this study, tapentadol ER at a mean dosage of $200 \mathrm{mg} /$ day was associated with a significant reduction in pain intensity from baseline to final evaluation in patients with moderatesevere chronic neck pain, $90 \%$ of whom were opioid-naïve. This dosage was lower than that documented (about $300 \mathrm{mg}$ / day) in other clinical trials on tapentadol ER for patients with chronic LBP, with or without a neuropathic pain component. ${ }^{39}$ However, in our study, the drug was well tolerated also in patients reaching the dosage of $400 \mathrm{mg} /$ day.

Tapentadol ER was effective in reducing the neuropathic component, as recorded by the DN4: $70 \%$ of enrolled patients 


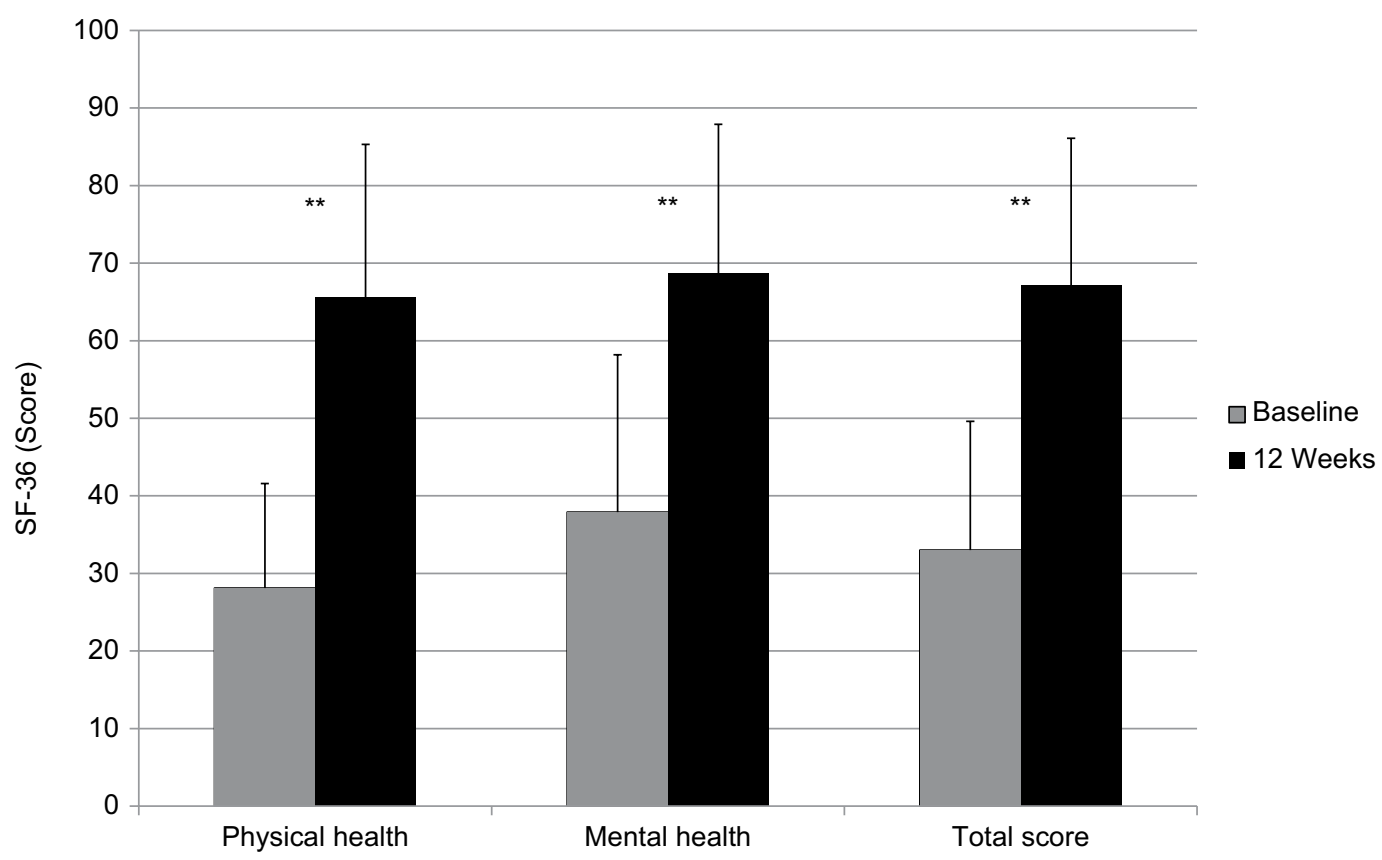

Figure 5 SF-36 physical and mental health and total score from baseline to week 12 (final evaluation).

Note: ${ }^{* *} P<0.01$ baseline-final improvement, paired $t$-test.

Abbreviation: SF-36, Short Form (36) Health Survey.

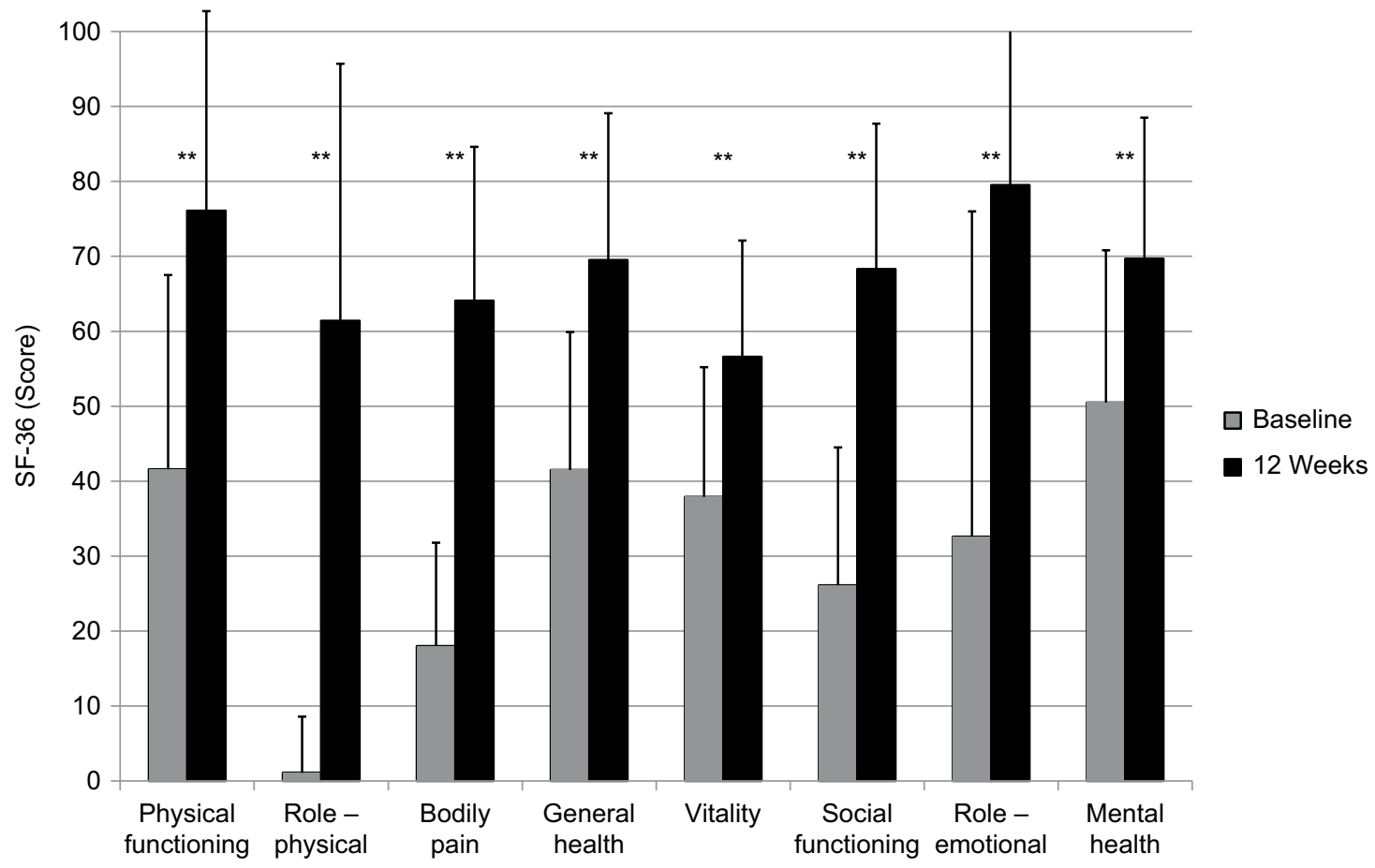

Figure 6 SF-36 scores from baseline to week 12 (final evaluation).

Note: ${ }^{* *} P<0.0$ I baseline-final improvement, paired $t$-test.

Abbreviation: SF-36, Short Form (36) Health Survey.

presented a positive DN4 score at baseline, which significantly reduced along the 12 weeks of treatment. The well-known efficacy of tapentadol ER on the neuropathic component of chronic pain is related to its ability to potentiate the noradrenergic inhibitory system, without activity on the serotonergic pathway, which in chronic conditions may also play a pronociceptive role.
Adequate management of patients with chronic pain includes the accurate assessment of their symptoms and function using validated tools. To this end, we used several disease-specific questionnaires for patients with spinal disorders. Neck ROM and the NDI are specifically used to evaluate the outcomes of surgical, physical, and pharmacological 
Table 3 Opioid-related symptoms at various time points

\begin{tabular}{|c|c|c|c|c|c|c|}
\hline Opioid-related symptoms, n (\%) & Week 0 & Week I & Week 2 & Week 4 & Week 8 & Week I2 \\
\hline Patients, $\mathrm{n}$ & 54 & 53 & 51 & 48 & 45 & 44 \\
\hline Nausea, n (\%) & $2(3.7)$ & $4(7.5)$ & $4(7.8)$ & $\mathrm{I}(2.1)$ & 0 & 0 \\
\hline Vomiting, n (\%) & 0 & $2(3.8)$ & I (2) & 0 & 0 & 0 \\
\hline Constipation, n (\%) & $3(5.6)$ & $3(5.7)$ & $3(5.9)$ & $3(6.2)$ & $4(8.9)$ & $4(9.1)$ \\
\hline Dry mouth, $\mathrm{n}(\%)$ & 0 & 0 & 0 & 0 & 0 & 0 \\
\hline Dizziness, n (\%) & $\mathrm{I}(\mathrm{I} .8)$ & $5(9.4)$ & $7(\mid 3.7)$ & $2(4.2)$ & $3(6.7)$ & $\mathrm{I}(2.3)$ \\
\hline Drowsiness, $\mathrm{n}(\%)$ & 0 & $4(7.5)$ & $4(7.8)$ & $I(2.1)$ & $\mathrm{I}(2.2)$ & 0 \\
\hline Headache, n (\%) & 0 & 0 & I (2) & 0 & 0 & 0 \\
\hline Sweating, n (\%) & 0 & 0 & 0 & 0 & 0 & 0 \\
\hline Other symptoms, n (\%) & 0 & 0 & 0 & 0 & 0 & 0 \\
\hline
\end{tabular}

Table 4 Frequency of use (\%) of other drugs at various time points

\begin{tabular}{|c|c|c|c|c|c|c|}
\hline Drugs, n (\%) & Week 0 & Week I & Week 2 & Week 4 & Week 8 & Week I2 \\
\hline Patients, $\mathrm{n}$ & 54 & 53 & 51 & 48 & 45 & 44 \\
\hline NSAIDs, n (\%) & $12(22.2)$ & I (I.9) & I (2) & 0 & 0 & 0 \\
\hline APAP, n (\%) & II (20.4) & $3(5.7)$ & $2(3.9)$ & $3(6.2)$ & $3(6.7)$ & $2(4.5)$ \\
\hline Antidepressants, n (\%) & $3(5.6)$ & $4(7.5)$ & $3(5.9)$ & $3(6.2)$ & $3(6.7)$ & $3(6.8)$ \\
\hline Anticonvulsants, n (\%) & $7(13)$ & $6(11.3)$ & $6(11.8)$ & $5(10.4)$ & $5(I I . I)$ & $5(11.4)$ \\
\hline Corticosteroids, n (\%) & $3(5.6)$ & I (I.9) & 0 & 0 & 0 & 0 \\
\hline Topical drugs, n (\%) & $2(3.7)$ & $2(3.8)$ & $2(3.9)$ & $3(6.2)$ & $3(6.7)$ & $3(6.8)$ \\
\hline Step II opioids, n (\%) & $6(11.1)$ & 0 & 0 & 0 & 0 & 0 \\
\hline Antiemetics, n (\%) & 0 & $3(5.7)$ & $2(3.9)$ & 0 & I (2.2) & 0 \\
\hline Laxatives, n (\%) & $\mathrm{I}(\mathrm{I} .8)$ & I (I.9) & I (2) & $3(6.2)$ & $3(6.7)$ & $3(6.8)$ \\
\hline
\end{tabular}

Abbreviations: NSAIDs, nonsteroidal anti-inflammatory drugs; APAP, acetaminophen.

approaches to patients with cervical diseases. Our results showed that patients can experience a significant increase in neck ROM after 3 months of treatment with tapentadol ER. Increased ROM was reported in all three cardinal planes of cervical motion. The plane that most improved for neck ROM was the coronal (nearly 35\% improvement in both sides of lateral bending), which was the less conserved at baseline (only $45 \%$ of residual lateral flexion). This result is in accordance with the functional anatomy of the spine. Lateral bending is a complex movement, usually coupled with some degree of vertebral rotation. During lateral flexion, indeed, the dimensions of intervertebral foramina on the ipsilateral side are reduced, with potential root compression and related neuropathic pain in patients with degenerative changes of the spine. On the other side, the lowest ROM gained was in flexion in the sagittal plane. However, it should be noted that flexion was the better-conserved ROM at baseline $(70.9 \%$ of maximum value), while on the same plane extension was reduced at baseline by about $45 \%$. In terms of percentage of ROM improvement, our results were better than those reported in the literature after anterior cervical decompression and fusion, in which the greatest ROM gain was $<15 \% .{ }^{40}$ Two possible explanations for these results are the different samples (surgical vs nonsurgical patients) and the potential observation that pharmacological treatment reduces pain intensity without the movement limitation related to cervical fusion.

Tapentadol ER significantly reduced NDI scores (from 55.6 at week 0 to 19.7 at week 12 ). These results suggest a reduction from complete disability $(>34)$ to moderate disability (range 15-24). In another study on patients with neck pain treated with opioids, success was defined as a 15-point or greater improvement in NDI. ${ }^{26} \mathrm{~A}$ decrease in disability suggests that patients had improved function and consequently improved quality of life. Indeed, in our study tapentadol ER was associated with significant improvement $n$ quality of life, as measured by the SF-36. Previous studies have shown a strong correlation between the NDI and SF-6D, a short version of the SF-36. ${ }^{41,42}$

Sleep disturbances are a recognized issue in patients with chronic pain. ${ }^{43}$ An indirect evaluation of efficacy of the analgesic treatment is represented by improvement in PSI. In particular, patients with cervical problems may suffer during the night, due to wrong postures, inadequate pillows, and poor pain relief. Indeed, sleep quality is one of the ten items of the NDI. In our study, PSI significantly improved by a mean of 4.5 points, corresponding to $70 \%$ of baseline value.

Overall, these results show that tapentadol ER is effective in managing severe chronic neck pain. Moreover, it was well accepted by patients, with a discontinuation rate lower 
than $20 \%$. Based on PGIC results, about $90 \%$ of patients rated their overall condition as much/very much improved. Given the relatively young age of our patients (mean age 56 years), which included people of working age, chronic use of opioids could be concerning, because of their impact on driving ability, the well-known risk of tolerance, dose escalation, opioid-induced hyperalgesia, and addiction. ${ }^{44}$ However, tapentadol ER does not affect driving ability in patients on stable doses. ${ }^{45}$ Moreover, compared with traditional $\mu$-opioid agonists during postmarketing surveillance, tapentadol ER was associated with the lowest risk of abuse. ${ }^{46}$

Our study is not without its limitations. These include the limited sample size, the open-label nature, and the lack of an active or placebo comparator. We recognize that in pharmacological trials in the field of pain, a large placebo response can be observed, which can be estimated as about $30 \%$ of efficacy. However, in our study the size of response to tapentadol ER was significantly higher, measured as about $90 \%$ of patients reporting $\geq 30 \%$ reduction.

This study had exploratory purposes; therefore, further studies are warranted in order to support this preliminary evidence on the effectiveness and safety of tapentadol ER in this indication. However, these findings support the hypothesis that patients with neck pain may benefit from tapentadol treatment for chronic moderate-severe pain, and adequate analgesia may significantly increase their functionality and quality of life.

\section{Acknowledgment}

We thank Luca Giacomelli, PhD for the useful discussion.

\section{Disclosure}

The authors report no conflicts of interest in this work.

\section{References}

1. Hoy DG, Protani M, De R, Buchbinder R. The epidemiology of neck pain. Best Pract Res Rheumatol. 2010;24(6):783-792.

2. Fejer R, Kyvik KO, Hartvingsen J. The prevalence of neck pain in the world population: a systematic critical review of the literature. Eur Spine J. 2006;15(6):834-848.

3. Lindegård A, Wahlström J, Hagberg M, Vilhelmsson R, Toomingas A, Tornqvist EW. Perceived exertion, comfort and working technique in professional computer users and associations with the incidence of neck pain upper extremity symptoms. BMC Musculoskelet Disord. 2012;13:38.

4. Hogg-Johnson S, van der Velde G, Carroll LJ, et al. The burden and determinants of neck pain in the general population: results of the Bone and Joint Decade 2000-2010 Task Force on Neck Pain and Its Associated Disorders. Spine (Phila Pa 1976). 2008;33(4 Suppl):S39-S51.

5. Teichtahl AJ, McColl G. An approach to neck pain for family physicians. Aust Fam Physician. 2013;42(11):774-777.

6. Iyer S, Kim HJ. Cervical radiculopathy. Curr Rev Musculoskelet Med. 2016;9(3):272-280.

7. Lluch E, Nijs J, De Kooning M, et al. Prevalence, incidence, localization, and pathophysiology of myofascial trigger points in patients with spinal pain: a systematic literature review. J Manipulative Physiol Ther. 2015;38(8):587-600.
8. Hush JM, Lin CC, Michaleff ZA, Verhagen A, Refshauge KM. Prognosis of acute idiopathic neck pain is poor: a systematic review and meta-analysis. Arch Phys Med Rehabil. 2011;92(5):824-829.

9. Arendt-Nielsen L, Graven-Nielsen T. Translational musculoskeletal pain research. Best Pract Res Clin Rheumatol. 2011;25(2):209-226.

10. Coluzzi F, Fornasari D. Dall'acuto al cronico: tapentadolo nelle fasi evolutive della patologia dolore. Fighting Pain. 2016;3(1):5-11.

11. Manchikanti L, Nampiaparampil DE, Candido KD, et al. Do cervical epidural injections provide long-term relief in neck and upper extremity pain? A systematic review. Pain Physician. 2015;18(1):39-60.

12. Falco FJ, Erhart S, Wargo BW, et al. Systematic review of diagnostic utility and therapeutic effectiveness of cervical facet joint interventions. Pain Physician. 2009;12(2):323-344.

13. Hu Y, Lv G, Ren S, Johansen D. Mid- to long-term outcomes of cervical disc arthroplasty versus anterior cervical discectomy and fusion for treatment of symptomatic cervical disc disease: a systematic review and meta-analysis of eight prospective randomized controlled trials. PLoS One. 2016;11(2): $\mathrm{e} 0149312$.

14. Phillips FM, Geisler FH, Gilder KM, Reah C, Howell KM, McAfee PC. Long-term outcomes of the US FDA IDE prospective, randomized controlled clinical trial comparing PCM cervical disc arthroplasty with anterior cervical discectomy and fusion. Spine (Phila Pa 1976). 2015;40(10):674-683.

15. Gross A, Langevin P, Burnie SJ, et al. Manipulation and mobilisation for neck pain contrasted against an inactive control or another active treatment. Cochrane Database Syst Rev. 2015;(9):CD004249.

16. Gross A, Kay TM, Paquin JP, et al. Exercises for mechanical neck disorders. Cochrane Database Syst Rev. 2015;1:CD004250.

17. Trinh K, Graham N, Irnich D, Cameron ID, Forget M. Acupuncture for neck disorders. Cochrane Database Syst Rev. 2016;(5):CD004870.

18. Monticone M, Ambrosini E, Cedraschi C, et al. Cognitive-behavioral treatment for subacute and chronic neck pain: a Cochrane review. Spine (Phila Pa 1976). 2015;40(19):1495-1504.

19. Childs JD, Cleland JA, Elliott JM, et al. Neck pain: clinical practice guidelines linked to the international classification of functioning, disability, and health from the orthopaedic section of the American Physical Therapy Association. J Orthop Sports Phys Ther. 2008;38(9):A1-A34.

20. National Institute for Health and Care Excellence. Neck pain - nonspecific. 2015. Available from: https://cks.nice.org.uk/neck-pain-nonspecific. Accessed January 27, 2017.

21. Wong JJ, Côté P, Ameis A, et al. Are non-steroidal anti-inflammatory drugs effective for the management of neck pain and associated disorders, whiplash-associated disorders, or non-specific low back pain? A systematic review of systematic reviews by the Ontario Protocol for Traffic Injury Management (OPTIMa) Collaboration. Eur Spine J. 2016;25(1):34-61.

22. National Institute for Health and Care Excellence. Neck pain - cervical radiculopathy. 2015. Available from: https://cks.nice.org.uk/neck-paincervical-radiculopathy. Accessed January 27, 2017.

23. Nijs J, Apeldoorn A, Hallegraeff H, et al. Low back pain: guidelines for the clinical classification of predominant neuropathic, nociceptive, or central sensitization pain. Pain Physician. 2015;18(3):E333-E346.

24. Malfliet A, Kregel J, Cagnie B, et al. Lack of evidence for central sensitization in idiopathic, non-traumatic neck pain: a systematic review. Pain Physician. 2015;18(3):223-236.

25. Ma K, Jiang W, Zhou Q, Du DP. The efficacy of oxycodone for management of acute pain episodes in chronic neck pain patients. Int J Clin Pract. 2008;62(2):241-247.

26. Kelly MP, Anderson PA, Sasso RC, Riew KD. Preoperative opioid strength may not affect outcomes of anterior cervical procedures: a post hoc analysis of 2 prospective, randomized trials. J Neurosurg Spine. 2015;23(4):484-489.

27. Suzan E, Treister R, Pud D, Haddad M, Eisenberg E. The effect of hydromorphone therapy on psychophysical measurements of the descending inhibitory pain systems in patients with chronic radicular pain. Pain Med. 2015;16(1):168-175.

28. Fornasari D. Pain pharmacology: focus on opioids. Clin Cases Miner Bone Metab. 2014;11(3):165-168. 
29. Afilalo M, Morlion B. Efficacy of tapentadol ER for managing moderate to severe chronic pain. Pain Physician. 2013;16(1):27-40.

30. Baron R, Jansen JP, Binder A, et al. Tolerability, safety, and quality of life with tapentadol prolonged release (PR) compared with oxycodone/ naloxone $\mathrm{PR}$ in patients with severe chronic low back pain with a neuropathic component: a randomized, controlled, open-label, phase 3B/4 trial. Pain Pract. 2016;16(5):600-619.

31. Van Seventer R, Vos C, Meerding W, et al. Linguistic validation of the DN4 for use in international studies. Eur J Pain. 2010;14(1): 58-63.

32. Vernon H, Mior S. The Neck Disability Index: a study of reliability and validity. J Manipulative Physiol Ther. 1991;14(7):409-415.

33. Cleland JA, Fritz JM, Whitman JM, Palmer JA. The reliability and construct validity of the Neck Disability Index and patient specific functional scale in patients with cervical radiculopathy. Spine (Phila Pa 1976). 2006,31(5):598-602.

34. Apolone G, Mosconi P. The Italian SF-36 Health Survey: translation, validation and norming. $J$ Clin Epidemiology. 1998;51(11): 1025-1036.

35. Kozma CM, Provenzano DA, Slaton TL, Patel AA, Benson CJ. Complexity of pain management among patients with nociceptive or neuropathic neck, back, or osteoarthritis diagnoses. J Manag Care Spec Pharm. 2014;20(5):455-466b.

36. Morlion B. Pharmacotherapy of low back pain: targeting nociceptive and neuropathic pain components. Curr Med Res Opin. 2011;27(1): $11-33$.

37. Faour M, Anderson JT, Haas AR, et al. Prolonged preoperative opioid therapy associated with poor return to work rates after single-level cervical fusion for radiculopathy for patients receiving workers' compensation benefits. Spine (Phila Pa 1976). 2017;42(2):E104-E110.
38. Coluzzi F, Raffa RB, Pergolizzi J, et al. Tapentadol prolonged release for patients with multiple myeloma suffering from moderate-to-severe cancer pain due to bone disease. J Pain Res. 2015;8:229-238.

39. Steigerwald I, Müller M, Davies A, et al. Effectiveness and safety of tapentadol prolonged release for severe, chronic low back pain with or without a neuropathic pain component: results of an open-label, phase 3B study. Curr Med Res Opin. 2012;28(6):911-936.

40. Landers MR, Addis KA, Longhurst JK, Vom Steeg BL, Puentedura EJ, Daubs MD. Anterior cervical decompression and fusion on neck range of motion, pain, and function: a prospective analysis. Spine $J$. 2013;13(11):1650-1658.

41. Carreon LY,Anderson PA, McDonough CM, Djurasovic M, Glassman SD. Predicting SF-6D utility scores from the Neck Disability Index and numeric rating scales for neck and arm pain. Spine. 2011;36(6):490-494.

42. Zheng Y, Tang K, Ye L, Ai Z, Wu B. Mapping the Neck Disability Index to SF-6D in patients with chronic neck pain. Health Qual Life Outcomes. 2016;14:21.

43. Marty M, Rozenberg S, Duplan B, Thomas P, Duquesnoy B, Allaert F. Quality of sleep in patients with chronic low back pain: a case-control study. Eur Spine J. 2008;17(6):839-844.

44. Maremmani I, Gerra G, Ripamonti IC, et al. The prevention of analgesic opioids abuse: expert opinion. Eur Rev Med Pharmacol Sci. 2015;19(21):4203-4206.

45. Sabatowski R, Scharnagel R, Gyllensvärd A, Steigerwald I. Driving ability in patients with severe chronic low back or osteoarthritis knee pain on stable treatment with tapentadol prolonged release: a multicenter, open-label, phase 3B trial. Pain Ther. 2014;3(1):17-29.

46. Butler SF, McNaughton EC, Black RA. Tapentadol abuse potential: a postmarketing evaluation using a sample of individuals evaluated for substance abuse treatment. Pain Med. 2015;16(1):119-130.

\section{Journal of Pain Research}

\section{Publish your work in this journal}

The Journal of Pain Research is an international, peer reviewed, open access, online journal that welcomes laboratory and clinical findings in the fields of pain research and the prevention and management of pain. Original research, reviews, symposium reports, hypothesis formation and commentaries are all considered for publication

\section{Dovepress}

The manuscript management system is completely online and includes a very quick and fair peer-review system, which is all easy to use. Visit http://www.dovepress.com/testimonials.php to read real quotes from published authors. 